\title{
Experience of Dental Caries among Aboriginal Children in Selangor, Malaysia
}

\author{
Rahimah Abdul KADIR, DDS (Indonesia), MSD (Indiana), \\ MPH (Michigan) and Ahmad Tajuddin YASSIN, \\ BDS (Singapore), DDPHRCS (England)
}

(Received 17 July and accepted 27 September 1990)

Key words: aborigines, dental caries, West Malaysia

\begin{abstract}
A cross-sectional survey involving 303 6-15-year-old aboriginal children was carried out in Selangor, West Malaysia. Dental caries status was assessed on the basis of the methods of the World Health Organization Oral Health Survey. The findings indicated a generally low prevalence of dental caries with a mean df of 4.94 for children below the age of 10 years. Mean DMFT and DMFS values of 1.71 and 3.22 , respectively, were also observed for the 6-15-year-old children.
\end{abstract}

\section{Introduction}

The aborigines of West Malaysia, officially known as the "Orang Asli," are believed to have settled in this region as early as 2,500 B.C. ${ }^{[1]}$. According to the 1986 census conducted by the Department of Orang Asli Affairs (JHEOA), there were 68,935 Orang Asli in West Malaysia comprising three ethnic groups: the Proto-Malays, Senois and Negritos ${ }^{[2]}$. Of these, 8,388 (12.1\%), mostly Proto-Malay tribes, are in Selangor.

In spite of efforts by the government of Malaysia to encourage them to adopt a modern lifestyle, the Orang Asli still prefer to retain their semi-primitive habits ${ }^{[3]}$. One of the barriers preventing these efforts may be a lack of understanding of their lifestyle, and their social, as well as medical and dental values. Too few studies have been done to shed light on these aspects, and in terms of dentistry, no baseline data have ever been reported.

In view of this background, efforts were made to conduct a dental survey with the following objectives:

(1) to determine the dental disease status of the Orang Asli children in Selangor

(2) to provide data for estimating the needs for dental treatment of this population

(3) to expose the children to members of the dental profession in order to reduce their fear and anxiety over dental treatment.

Department of Community Dentistry, Faculty of Dentistry, University of Malaya

This study was funded by a Vote $F$ grant from the University of Malaya.

To whom all correspondence should be addressed: Dr. Rahimah Abdul Kadir, Department of Preventive Dentistry, Faculty of Dentistry, University of Malaya, 59100 Kuala Lumpur, MALAYSIA. 
In many instances, this was the first exposure of its kind the population had received. This article reports only on the dental caries status of these aboriginal children. Their periodontal status has been reported previously ${ }^{[4]}$.

\section{Materials and Methods}

The sampling frame of this study has been reported ${ }^{[3]}$ previously. For dental caries, a cross-sectional picture of the caries status of the Selangor Orang Asli children was assessed on the basis of the World Health Organization definitions using the DMF Index ${ }^{[5]}$. Examination was carried out using a chair-table with natural daylight as the major source of light. All teeth were examined using a plane mouth mirror and a sharp explorer. No radiographs were taken. Inter- and intra-examiner errors were kept to a minimum through repeated calibrations prior to the survey and, duplicate examinations on 5\% of the sample on the examination day. A mean difference of $2-4 \%$ for intra-examiner comparison was observed.

All observations collected in this survey were recorded directly onto the survey form. Data analysis was done on an IBM PC microcomputer using appropriate statistical software.

\section{Results}

Table 1 shows the number of 6-15-year-old Orang Asli children enrolled and examined according to schools. The five largest schools, with a total enrolment of 567 children, comprising $50.9 \%$ of the total child population of this tribe in Selangor, were selected for the survey. However, only 303 children (53.4\%) comprising 152 boys and 151 girls, were examined. The other $46.6 \%$ of the children were either absent or had left school for unknown reasons on the day of the examination.

Table 2 presents data on caries for primary teeth of Orang Asli children below 10 years of age. In all, $87.3 \%$ of the children examined had at least one carious primary tooth. The mean $\mathrm{df}$ teeth for the 6-9-year-old group was 4.9 , with a mean of 4.2 decayed teeth, and 0.7 filled teeth.

With regard to caries of permanent teeth, 162 (53.5\%) of the 303 children examined had at least one carious tooth (Table 3). The mean DMF value was 1.7, and the mean number of DMF surfaces was 3.5. The highest mean DMF teeth and surface values, 3.6 and 6.6, respectively, were observed in the 15-year-old group.

Sex-specific comparison showed that the prevalence of dental caries in the

Table 1 Sample distribution

\begin{tabular}{lccc}
\hline \multicolumn{1}{c}{ SCHOOL } & ENROLMENT & \multicolumn{2}{c}{ TOTAL EXAMINED } \\
& & Number & Percentage \\
\hline Bukit Kemandul & 84 & 54 & 62.8 \\
Bukit Tadom & 94 & 34 & 36.2 \\
Bukit Bangkong & 110 & 73 & 75.4 \\
Bukit Tampoi & 122 & 56 & 62.3 \\
Bukit Lanjan & 157 & 303 & 35.7 \\
\hline Total & 567 & & 53.2 \\
\hline
\end{tabular}


Table 2 Dental caries of primary teeth in children below 10 years of age

\begin{tabular}{cccccc}
\hline $\begin{array}{c}\text { AGE } \\
\text { (YEARS) }\end{array}$ & EXAMINED & WITH dft & \multicolumn{3}{c}{ MEAN } \\
\hline 6 & & N (\%) & $\mathrm{dt}$ & $\mathrm{ft}$ & dft (s. d) \\
7 & 15 & $13(86.7)$ & 6.1 & 0.2 & $6.3(5.9)$ \\
8 & 31 & $30(96.7)$ & 5.5 & 0.1 & $5.6(5.3)$ \\
9 & 53 & $48(90.6)$ & 3.9 & 1.0 & $4.9(4.1)$ \\
\hline $6-9$ & 58 & $46(79.3)$ & 3.1 & 1.0 & $4.2(3.8)$ \\
\hline
\end{tabular}

Table 3 Dental caries of permanent teeth in 6-15-year-old aboriginal children

\begin{tabular}{ccccccc}
\hline AGE & No & WITH DMFT & \multicolumn{4}{c}{ MEAN } \\
(YEARS) & EXAM. & N (\%) & DMFT (s. d) & DMFS (s. d) \\
\hline 6 & 15 & $9(60.0)$ & 0.5 & $(1.1)$ & 1.9 & $(1.8)$ \\
7 & 31 & $7(22.6)$ & 1.1 & $(1.4)$ & 2.0 & $(2.2)$ \\
8 & 53 & $30(56.6)$ & 1.2 & $(1.5)$ & 2.1 & $(3.1)$ \\
9 & 58 & $25(43.1)$ & 1.3 & $(1.2)$ & $2.3(3.5)$ \\
10 & 34 & $21(61.8)$ & 1.5 & $(1.6)$ & 2.5 & $(3.7)$ \\
11 & 38 & $18(47.4)$ & 1.6 & $(1.6)$ & 2.9 & $(4.3)$ \\
12 & 38 & $25(65.8)$ & 1.7 & $(1.8)$ & 3.6 & $(5.4)$ \\
13 & 22 & $16(72.7)$ & 2.7 & $(2.6)$ & 5.0 & $(4.3)$ \\
14 & 7 & $6(85.7)$ & 2.7 & $(2.4)$ & 6.2 & $(5.1)$ \\
15 & 7 & $5(71.4)$ & 3.6 & $(2.3)$ & 6.6 & $(5.4)$ \\
\hline $6-15$ & 303 & $162(53.5)$ & 1.7 & $(1.7)$ & 3.5 & $(3.8)$ \\
\hline
\end{tabular}

Table 4 Comparison of dental caries prevalence in Malaysian surveys between 1971 and 1989

\begin{tabular}{lcccc}
\hline \multicolumn{1}{c}{ Region } & Year & $\begin{array}{c}\text { mean dft* } \\
\text { (s. d) }\end{array}$ & $\begin{array}{c}\text { Mean DMFT** } \\
\text { (s. d) }\end{array}$ & \% Affected*** \\
\hline West Msia & 1971 & $4.6(2.5)$ & $3.0(3.3)$ & 88.9 \\
Sarawak & 1981 & $4.6(3.2)$ & $3.1(3.8)$ & 89.6 \\
Sabah & 1985 & $5.6(3.4)$ & $4.3(4.2)$ & 94.4 \\
Asli WM & 1988 & $4.9(4.8)$ & $1.7(1.7)$ & 86.1 \\
\hline
\end{tabular}

* below 10 years old

** 6 to 15 years old

*** with one or more df or/and DMF teeth

permanent dentition was consistently higher in girls (59.6\%) than in boys (47.4\%) (Fig. 1). The overall mean DMF for boys was $1.3(\mathrm{s.d}=1.6)$, whereas that for girls was $2.0(\mathrm{~s} . \mathrm{d}=2.0)$.

\section{Discussion}

The findings of this study show that the prevalence of dental caries is generally low among the Proto-Malay children in Selangor. Previous national surveys on other ethnic groups in West Malaysia $(1971)^{[6]}$, Sarawak $(1981)^{[7]}$ and Sabah $(1985)^{[8]}$ showed that while the mean df scores were similar, the mean DMFT scores $(3.0,3.1,4.3$, respectively) were much higher than the value of 1.7 found in the present study (Table 4). The relatively high df scores in the 6-9-year-old children were probably due to lack of oral hygiene and dental awareness among parents and the children themselves ${ }^{[9,10]}$. The low DMFT scores, on the other hand, can be attributed in part to their semiprimitive lifestyle and the diet that they have 


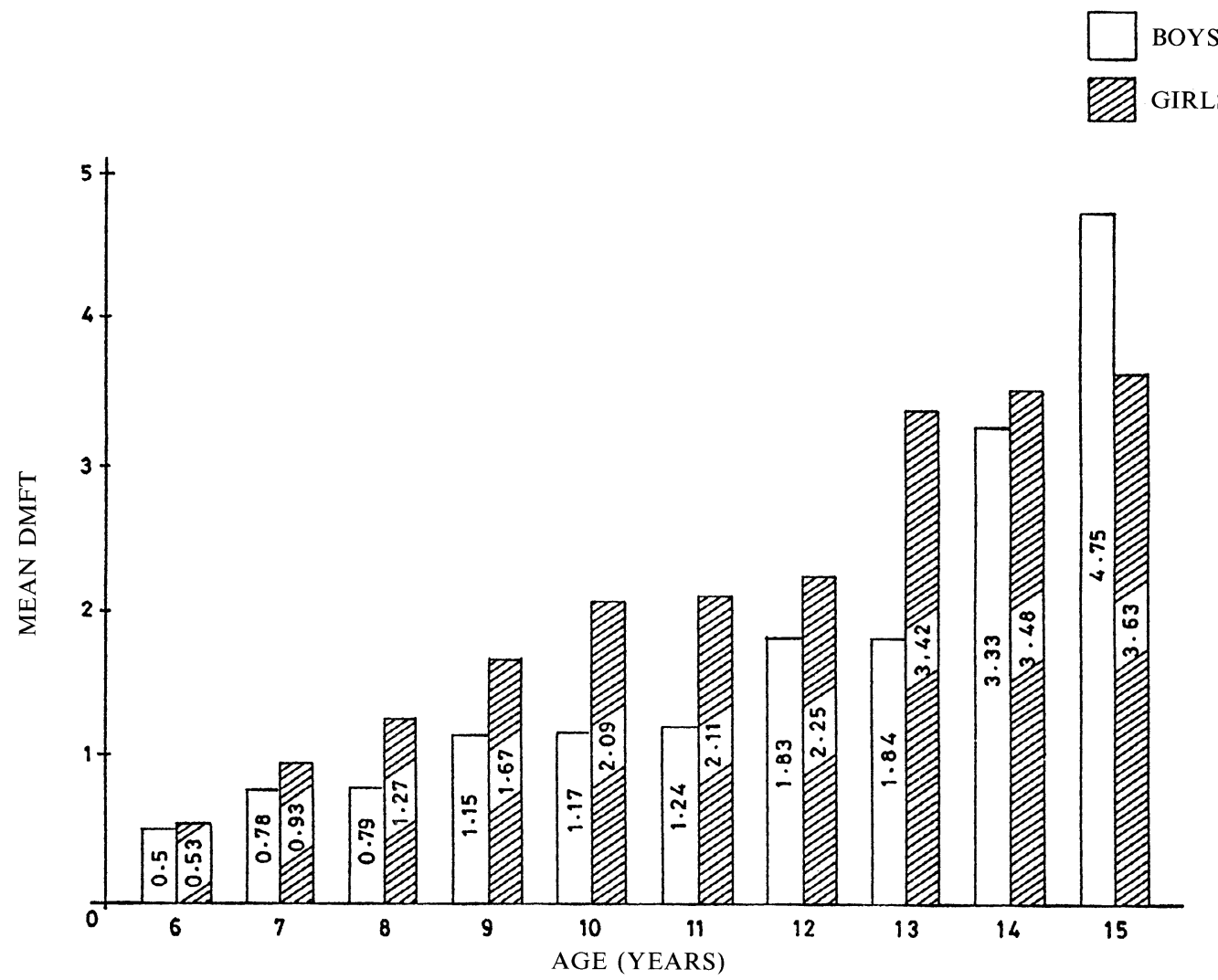

Fig. 1 Mean DMFT of 6-15-year-old aboriginal children by sex

chosen to retain $^{[3,9,11,12]}$. Studies have shown that the diet of the Orang Asli has remained unchanged ${ }^{[11,12]}$, being high in carbohydrate and fiber but containing very little or no sugar.

It has to be recognized that since the methodologies used were different, direct comparisons amongst the available epidemiological studies conducted in Malaysia seem inappropriate. Nevertheless, the present findings provide an overview of the dental caries status of 6-15-year-olds among different racial groups in Malaysia. Such comparison is an important tool for program planning ${ }^{[13]}$.

With regard to the DMF surfaces, no previous data are available for comparison, although the findings appear to be comparable to those observed among 6-14-year-old Australian aboringines (mean DMFS 3.5 vs. 3.8, respectively) ${ }^{[14]}$. Collection of dental caries data by surfaces is important, especially in groups that reflect a low DMF prevalence, in order to identify surfaces at risk so that primary prevention, such as the use of fissure sealants, can be implemented ${ }^{[13]}$.

The higher incidence of dental caries in girls above the age of 10 years is consistent with other studies ${ }^{[15,16]}$. This has been suggested to be due to the earlier eruption of teeth in girls and hence their longer period of tooth exposure in the oral environment. The lower incidence at the age of 15 years, on the other hand, 
appear to indicate that girls are generally more conscious about the esthetic appearance of their teeth.

The overall favorable picture regarding the dental caries status of Orang Asli children has implications in terms of future planning of dental service programs. Currently, the dental clinic of the Gombak Aborigine Hospital, and to a limited extent the government dental mobile clinics, provide curative treatment for those in need of $i t^{[17]}$. Unfortunately, such services can be provided only to those few who have access to them. In view of the caries situation, it appears that curative work is not a priority. On the other hand, preventive programs, such as dental health education, appear to be necessary in an effort to promote dental awareness among the Orang Asli and subsequently to improve their dental health from early childhood.

The present study has provided valuable data for future similar studies. The sampling problem appears to be an inherent one in any aboriginal study ${ }^{[10,11]}$. This, together with the problems of accessibility, communication and general attitude of these aborigines, should serve to caution future investigators at the planning stage. In spite of the efforts made to maximize the extent of subject participation in the present study, a high absentee rate seems to be beyond the control of the investigators. Nevertheless, it is thought that the sample size available should still be sufficient to provide baseline data useful for program planning.

\section{Acknowledgements}

We express our gratitude to the University of Malaya for funding this project, and the JHEOA and Dental Division of the Malaysian Ministry of Health for their kind cooperation.

\section{References}

[1] Williams-hunt, P.D.R.: An introduction to the Malayan aborigines. Malayan Govt. Press: Kuala Lumpur, 1952

[2] Department of Orang Asli Affairs. 1986 Orang Asli Census. JHEOA: Kuala Lumpur, 1986 (Unpublished Document)

[3] Jones, A.: The Orang Asli: An outline of their progress in modern Malaya, JSAH, 9, 286-305, 1968

[4] Rahimah, A.K. and Ahmad, T.Y.: Periodontal status (CPITN) of six-to-fifteen-year-old West Malaysian aborigines (Proto-Malays), J. Nihon Univ. Sch. Dent., 31, 612-618, 1989

[5] Oral Health Surveys: Basic Methods, 3rd ed., Geneva: Oral Health Unit, World Health Organization, 1986

[6] Dental epidemiological survey of schoolchildren in West Malaysia, August 1970-May 1971. Kuala Lumpur: Dental Division, Ministry of Health, 1972

[7] Dental epidemiological survey in Sarawak, Kuala Lumpur: Dental Division, Ministry of Health, 1983

[8] Dental epidemiological survey in Sabah, Kuala Lumpur: Dental Division, Ministry of Health, 1985

[9] Abdul-Kadir, R. and Adnan, N.Md.: Dental caries experience of 7 to 12 years old West Malaysian aborigines, Trop. Dent. J., 12, 7-12, 1989

[10] Chen, J.A.: Dental status of the Penans along the Melinau and Terawan Rivers, Baram, Sarawak, Med. J. Msia., 41, 225-229, 1986

[11] Bolton, J.M.: Food taboos among the Orang Asli in West Malaysia: A potential nutritional 
hazard, Am. J. Clin., Nutr., 25, 789-799, 1972

[12] Robson, P., Bolton, J.M. and Dugdale, A. E.: The nutrition of the Malaysian aboriginal children, Am. J. Clin. Nutr., 26, 95-100, 1973

[13] Prevention in Oral Diseases: Geneva: World Health Organization, 1988

[14] Cooper, M.H., Schamschula, R.G. and Craig, G.G.: Caries experience of aboriginal children in the Orana Region of New South Wales, Aust. Dent. J., 32, 292-294, 1987

[15] Klein, H. and Palmer, C.E.: Studies on dental caries: VII. Sex differences in dental caries experience of elementary school children, Pub. Health Rep., 53, 1685-1690, 1938

[16] Sloman, E.: Sex and age factors in the incidence of dental caries, J. Am. Dent. Assoc., 28, 441-444, 1941

[17] Bolton, J.M.: Medical services to the aborigines in West Malaysia, Brit. Med. J., 2, 818-823, 1968 